\title{
PENGUKURAN KONSENTRASI PARTIKEL ASAP ROKOK DENGAN MENGGUNAKAN P-TRAK
}

\author{
Verna Albert Suoth ${ }^{1)}$, Maria D. Bobanto ${ }^{1)}$ \\ 1) Jurusan Fisika, FMIPA, Unsrat, Manado \\ e-mail: vernasuoth@yahoo.co.id; bennylumi@gmail.com
}

\begin{abstract}
ABSTRAK
Penelitian ini bertujuan untuk menentukan konsentrasi partikel pada asap rokok pada beberapa sampel rokok yang menggunakan filter dan sampel rokok tersebut merupakan rokok yang beredar di Indonesia. Ada 4 sampel rokok berfilter yang digunakan yakni filter $\mathrm{x}$, filter B, filter DE, dan filter DF. Jumlah konsentrasi partikel asap rokok diukur dengan menggunakan P-Track. Hasil penelitian yang di dapat bervariasi bergantung dari karakteristik filter yang ada pada masing-masing rokok tersebut. Konsentrasi partikel asap rokok yang terukur dengan menggunakan beberapa filter didapatkan bahwa dengan menggunakan Filter B akan mendapatkan konsentrasi partikel paling tinggi yaitu $384.100 \mathrm{pt} / \mathrm{cc}$ sedangkan Filter DE konsentrasi partikel $234.000 \mathrm{pt} / \mathrm{cc}$ untuk Filter DF konsentrasi partikel $204.400 \mathrm{pt} / \mathrm{cc}$ dan Filter X konsentrasi partikel $43.320 \mathrm{pt} / \mathrm{cc}$. Faktor emisi partikel asap rokok yang dikeluarkan oleh batang rokok filter B lebih besar dibanding dengan filter lain oleh karena pada masing-masing filter memiliki karakteristik yang berbeda sehingga asap yang dikeluarkan akan sangat berbeda. Dari data tersebut dapat diketahui tingkat bahaya partikel asap rokok sebanding dengan banyaknya asap rokok yang masuk ke detector.
\end{abstract}

Kata kunci: P-Trak, konsentrasi Partikel, asap rokok

\section{SMOKE PARTICLE CONCENTRATION MEASURING USING P-TRAK}

\begin{abstract}
This research aims to determine the concentration of particles in cigarette smoke in some samples of cigarettes and cigarette samples using the filter is a cigarette that circulated in Indonesia. There are 4 samples of filtered cigarettes used the filter $\mathrm{x}$, filter B, filter DE, and DF filter. The amount of smoke particle concentrations were measured by using the P-Track. Results of research on may vary depending on the characteristics of the existing filter on each of these cigarettes. The concentration of particles of cigarette smoke measured by using multiple filters found that by using Filter B will get a concentration of particles highest of $384.100 \mathrm{pt} / \mathrm{cc}$ while Filter DE particle concentration of $234.000 \mathrm{pt} / \mathrm{cc}$ to filter DF particle concentration 204.400 $\mathrm{pt} / \mathrm{cc}$ and Filter X concentration of particles $43.320 \mathrm{pt} / \mathrm{cc}$. Cigarette smoke particles emission factors released by cigarette filter rod B is greater than the other filters because at each filter has different characteristics so that the smoke released will be very different. From these data it can be seen the danger level of cigarette smoke particles is proportional to the number of cigarette smoke coming into the detector.
\end{abstract}

Keywords: P-Trak, the concentration of particles, cigarette smoke

\section{PENDAHULUAN}

Pencemaran udara saat ini telah mencapai tingkat yang meresakan. Pencemaran udara diartikan sebagai masuknya zat, energi, atau komponen lain ke dalam udara ambein oleh kegiatan manusia sehingga mutu udara ambient turun sampai ke tingkat tertentu yang menyebabkan udara ambient tidak dapat 
memenuhi fungsinya. Pencemaran udara tidak hanya berupa asap mesin pabrik atau mesinmesin kendaraan saja, namun juga asap asap rokok yang dapat kita temui dimana-mana, sayangnya dampak buruk akibat asap rokok tidak hanya ditanggung penikmat saja namun orang-orang sekitar yang tidak merokok yang ikut menghisap asap rokok atau disebut perokok pasif. Merokok telah diketahui dapat menyebabkan gangguan kesehatan. Gangguan kesehatan ini dapat disebabkan olehnikotin yang berasal dari asap rokok yang dihisap oleh perokok. Dengandemikian penderita tidak hanya perokok sendiri (perokok aktif) tetapi juga orang yang berada di lingkungan asap rokok(Environmental Tobacco Smoke) atau disebut dengan perokok pasif. Gangguan kesehatan yang ditimbulkan dapatberupa bronkitis kronis, emfisema, kanker paru-paru, larink, mulut, faring, esofagus, kandung kemih, penyempitanpembuluh nadi dan lainlain.Namun demikian masih banyak orang baik laki-laki maupun perempuan yang belum atautidak dapat meninggalkan kebiasaan merokok ini.

Merokok adalah membakar tembakau yang kemudian diisap asapnya, baik menggunakan rokok maupun menggunakan pipa.Temperatur pada sebatang rokok yang tengah dibakar adalah $900^{\circ} \mathrm{C}$ untuk ujung rokok yang dibakar dan $30^{\circ} \mathrm{C}$ untuk ujung rokok yang terselip diantara bibir perokok. Asap rokok yang diisap atau asap rokok yang dihirup melalui dua komponen: komponen yang lekas menguap berbentuk gas dan komponen yang bersama gas terkondensasi menjadi komponen partikulat. Dengan demikian asap rokok yang diisap dapat berupa gas sejumlah $85 \%$ dan sisanya berupa partikel. Partikel merupakan unsur butir (dasar) benda atau bagian benda yang sangat kecil dan berdimensi; materi yang sangat kecil, seperti butir pasir, elektron, atom, atau molekul.Pada penelitian ini akan mengukur berapa jumlah konsentrasi patikel yang terkandung pada asap rokok. Pada asap rokok yang yang diasumsikan bulat memiliki diameter partikel rata-rata $0,01 \mu \mathrm{m}-1 \mu \mathrm{m}$.

\section{Material dan Metode}

Untuk mendapat tujuan yang ingin dicapai dalam penelitian ini pengukuran konsentrasi partikel asap rokok yang terhirup oleh manusia. Percobaan yang dilakukan adalah mengukur jumlah partikel asap yang keluar melalui filter. Pengukuran ini dengan menguji 4 batang rokok menggunakan filter dengan karakteristik yang berbeda yaitu Filter $\mathrm{X}$ pada rokok, Filter tipe B, Filter tipe DE dan Filter Tipe DF. Percobaan ini dilakukan dengan sampai rokok tersebut habis terbakar dan rokok yang digunakan memiliki panjang 5 $\mathrm{cm}$ dengan waktu tempu antara 10 sampai 12 menit. Dengan menenpatkan ujung sensor pendeteksi partikel asap rokok pada selang maka akan mengukur jumlah particle dalam pt/cc (partikel per centimeter cubic).

Alat pengukuran partikel asap rokok ini terdiri dari 3 buah selang yang disambung berjejeran mulai dari yang berdiameter paling kecil sampai berdiameter paling besar. Ujung selang berdiameter kecil untuk masuknya asap rokok kemudian pada ujung selang yang paling besar akan dihubungkan ke pompa pengisap dan pada selang yang berdiameter $2,5 \mathrm{~cm}$ diberi lubang dengan diameter $0.8 \mathrm{~mm}$ sebagai tempat untuk memasukkan ujung sample probe dari P-Trak. Dan selanjutnya PTrak diset pengukuran partikel asap dengan pembacaan setiap 10 detik sepanjang $5 \mathrm{~cm}$ pada setiap batang rokok yang dibakar. Gambar 1 ditampilkan desain peralatan yang digunakan.

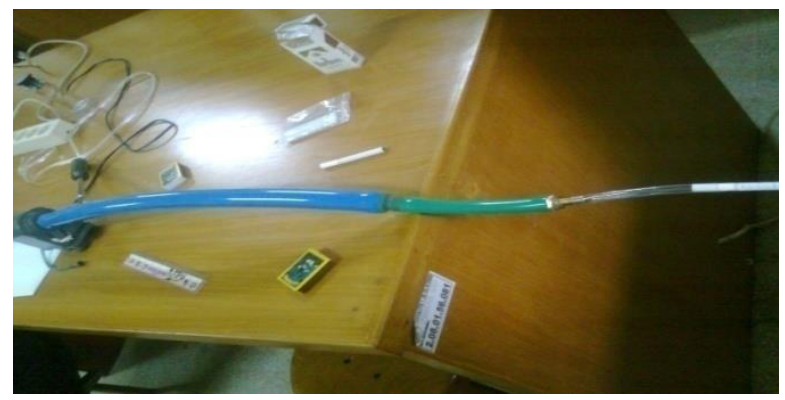

Gambar 1. Desain Peralatan

\section{HASIL DAN PEMBAHASAN Analisa Partikel Pada Asap Rokok}

Setelah dilakukan pengukuran jumlah konsentrasi partikel asap rokok pada 4 batang rokok yang dibedakan pada filter dengan karakteristik filter yang berbeda, maka berdasarkan hasil pengukuran dapat dianalisa faktor emisi partikel pada setiap batang rokok adalah sebagai berikut:

$$
\mathrm{E}_{\mathrm{p}}=\mathrm{P}_{\mathrm{t}} \frac{V_{\text {total }}}{T_{\text {total }}}
$$

dimana: $E p=$ faktor emisi partikel pada batang rokok

Total partikel dalam setiap pembakaran rokok, 


$$
\begin{aligned}
& \mathrm{P}_{\mathrm{t}}=\int_{t(0)}^{t(n)} C(t) \cdot d t=C t \\
& \mathrm{Pt}=\mathrm{C} . \mathrm{t}
\end{aligned}
$$

dengan : $\mathrm{P}_{\mathrm{t}}=$ Konsentrasi partikel $\left(\frac{p t}{c c} s\right)$

$$
\mathrm{C}(\mathrm{t})=\text { Konsentrasi Partikel }\left(\frac{p t}{c c}\right)
$$$$
1 \mathrm{cc}=1 \mathrm{~cm}^{3}
$$

Sedangkan volume pada pada selang sebagai media untuk mengalir asap adalah:

$$
\begin{aligned}
\mathrm{V}_{\text {total }} & =\mathrm{Q}_{\mathrm{t}} \mathrm{t} \\
\mathrm{Q} & =\mathrm{v} . \mathrm{A}
\end{aligned}
$$

dengan : $\mathrm{Q}_{\mathrm{t}}=$ Debit asap rokok

$$
\begin{aligned}
\mathrm{t}= & \text { Waktu pembakaran rokok } \\
\mathrm{v}= & \text { Kecepatan aliran udara asap } \\
& \text { rokok adalah } 0,1 \mathrm{~m} / \mathrm{s}=10^{-} \\
& 3 \mathrm{~cm} / \mathrm{s}
\end{aligned}
$$

$\mathrm{A}=$ Luas selang.

Maka debit pada asap rokok yang mengalir melalui selang adalah:

- Debit pada Selang 1 dengan diameter 2,5 $\mathrm{cm}$

$$
\begin{aligned}
\mathrm{Q}_{1} & =\mathrm{v} \mathrm{A_{1 }}=\mathrm{v} \pi \frac{d_{1}^{2}}{4} \\
& =10^{-3} \mathrm{~cm} / \mathrm{s} \cdot 3,14 \cdot \frac{2,5^{2}}{4} \mathrm{~cm}^{2} \\
& =4,91 \times 10^{-3} \frac{\mathrm{cm}}{\mathrm{s}}
\end{aligned}
$$

- Debit pada Selang 2 dengan diameter 1,5 $\mathrm{cm}$

$$
\begin{aligned}
\mathrm{Q}_{2} & =\mathrm{v} \mathrm{A}_{1}=\mathrm{v} \pi \frac{d_{1}^{2}}{4} \\
& =10^{-3 \mathrm{~cm}} / \mathrm{s} \cdot 3,14 \cdot \frac{1,5^{2}}{4} \mathrm{~cm}^{2} \\
& =1,77 \times 10^{-3} \frac{\mathrm{cm}^{3}}{\mathrm{~s}}
\end{aligned}
$$

- Debit pada Selang 3 dengan diameter 0,8 $\mathrm{cm}$

$$
\begin{aligned}
\mathrm{Q}_{3} & =\mathrm{v} \mathrm{A}_{1}=\mathrm{v} \pi \frac{d_{1}^{2}}{4} \\
& =10^{-3} \mathrm{~cm} / \mathrm{s} \cdot 3,14 \cdot \frac{0,8^{2}}{4} \mathrm{~cm}^{2} \\
& =0,50 \times 10^{-3} \frac{\mathrm{cm}}{\mathrm{s}}
\end{aligned}
$$

Sehingga didapat debit total adalah

$$
\begin{aligned}
\mathrm{Q}_{\text {total }} & =\left(\mathrm{Q}_{1}+\mathrm{Q}_{2}+\mathrm{Q}_{3}\right) \\
& =\left(4,91 \times 10^{-3}+1,77 \times 10^{-3}+0,50 \times 10^{-3}\right) \mathrm{cm}^{3} \\
& =7,18 \times 10^{-3} \frac{\mathrm{cm}^{3}}{\mathrm{~s}}
\end{aligned}
$$

\section{Menentukan Faktor Emisi Partikel Pada Batang Rokok}

Faktor Emisi pada batang rokok adalah sbb:

\section{a. Rokok Filter X}

Pada saat rokok dengan fiter $\mathrm{x}$ dibakar maka dapat dilihat jumlah partikel yang dihasilkan pada batang rokok ini berdasarkan waktu yang di tempu selama pembakaran dapat dilihat pada gambar 2 .

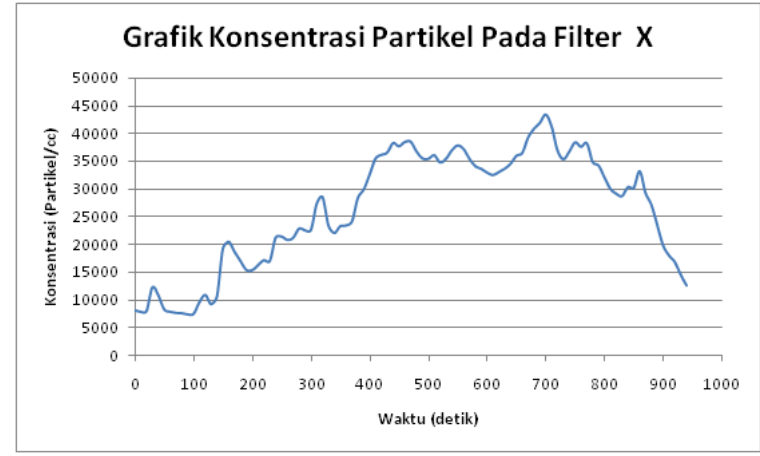

Gambar 2. Grafik Filter $x$

Diketahui waktu total pengukuran rokok filter $\mathrm{x}$ adalah $\mathrm{t}=940 \mathrm{~s}$

$$
\begin{aligned}
\mathrm{P}_{\mathrm{t}}=\int_{t(0)}^{t(n)} C(t) \cdot d t=C t \\
=25.021 \cdot 530 \frac{\mathrm{pt}}{c c} \mathrm{~s} \\
\mathrm{~V}_{\text {total }} \quad=\mathrm{Q}_{\text {total }} \cdot \mathrm{t} \\
=7,18 \times 10^{-3} \frac{\mathrm{cm}^{3}}{\mathrm{~s}} \times 940 \mathrm{~s} \\
=6,75 \mathrm{~cm}^{3} \\
\mathrm{E}_{\mathrm{p}} \quad=\mathrm{P}_{\mathrm{t}} \frac{V_{\text {total }}}{T_{\text {total }}} \\
=25.021 .530 \frac{\mathrm{pt}}{\mathrm{cm}^{3}} \mathrm{~s} \frac{6,75 \mathrm{~cm}^{3}}{940 \mathrm{~s}} \\
=179.675,88 \mathrm{pt} \approx 179.676 \mathrm{pt}
\end{aligned}
$$

Faktor emisi partikel yang dikeluarkan pada rokok filter x adalah $179.676 \mathrm{pt}$

\section{b. Rokok Filter B}

Pada saat rokok dengan fiter B dibakar maka dapat dilihat jumlah partikel yang dihasilkan pada batang rokok ini berdasarkan waktu yang di tempu selama pembakaran dapat dilihat pada gambar 3 .

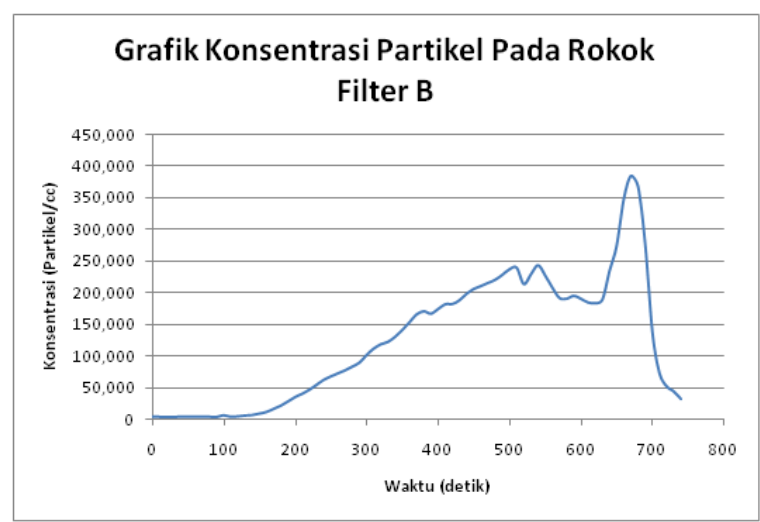

Gambar 3 Grafik Filter B

Diketahui waktu total pengukuran rokok filter $\mathrm{B}$ adalah $\mathrm{t}=740 \mathrm{~s}$

$$
\begin{aligned}
& \mathrm{P}_{\mathrm{t}}=\int_{t(0)}^{t(n)} C(t) \cdot d t=C t \\
& =92.984 .120 \frac{p t}{c c} \mathrm{~s} \\
& \mathrm{~V}_{\text {total }}=\mathrm{Q}_{\text {total }} \mathrm{t}
\end{aligned}
$$




$$
\begin{aligned}
& =7,18 \times 10^{-3} \frac{\mathrm{cm}^{3}}{\mathrm{~s}} \times 740 \mathrm{~s} \\
& =5,31 \mathrm{~cm}^{3} \\
\mathrm{E}_{\mathrm{p}} \quad & \mathrm{P}_{\mathrm{t}} \frac{V_{\text {total }}}{T_{\text {total }}} \\
& =92.984 .120 \frac{\mathrm{pt}}{\mathrm{cm}^{3}} \mathrm{~s} \frac{5,31 \mathrm{~cm}^{3}}{740 \mathrm{~s}} \\
& =667.223,88 \mathrm{pt} \approx 667.224 \mathrm{pt}
\end{aligned}
$$

Faktor emisi partikel yang dikeluarkan pada rokok filter B adalah $667.224 \mathrm{pt}$

\section{c. Rokok Filter DE}

Pada saat rokok dengan fiter DE dibakar maka dapat dilihat jumlah partikel yang dihasilkan pada batang rokok ini berdasarkan waktu yang di tempu selama pembakaran dapat dilihat pada Gambar 4.

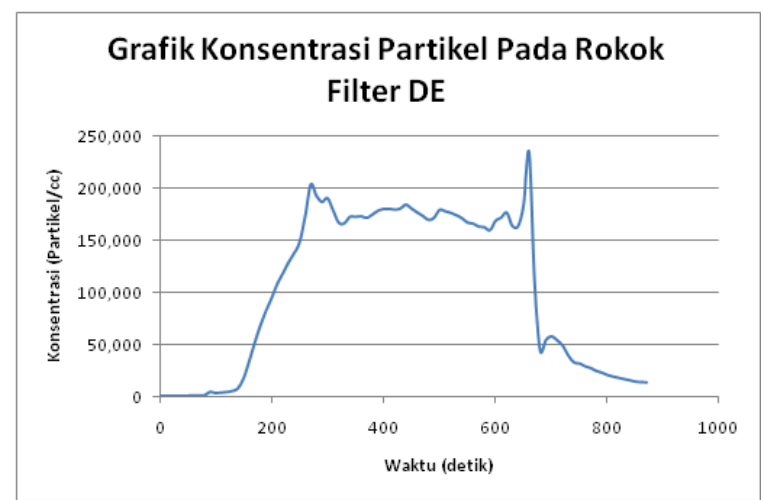

Gambar 4. Grafik Filter DE

Diketahui waktu total pengukuran rokok filter DE adalah $\mathrm{t}=870 \mathrm{~s}$

$$
\begin{aligned}
\mathrm{P}_{\mathrm{t}}=\int_{t(0)}^{t(n)} C(t) \cdot d t=C t \\
=89.973 \cdot 740 \frac{\mathrm{pt}}{c c} \mathrm{~s} \\
\mathrm{~V}_{\text {total }} \quad=\mathrm{Q}_{\text {total }} \cdot \mathrm{t} \\
=7,18 \times 10^{-3} \frac{\mathrm{cm}^{3}}{\mathrm{~s}} \times 870 \mathrm{~s} \\
=6,25 \mathrm{~cm}^{3} \\
\mathrm{E}_{\mathrm{p}} \quad=\mathrm{P}_{\mathrm{t}} \frac{V_{\text {total }}}{T_{\text {total }}} \\
=89.973 .740 \frac{\mathrm{pt}}{\mathrm{cm}} \mathrm{s} \frac{6,25 \mathrm{~cm}^{3}}{870 \mathrm{~s}} \\
=646.363,07 \mathrm{pt} \approx 646.363 \mathrm{pt}
\end{aligned}
$$

Faktor emisi partikel yang dikeluarkan pada rokok filter DE adalah $646.363 \mathrm{pt}$

\section{d. Rokok Filter DF}

Pada saat rokok dengan filter DE dibakar maka dapat dilihat jumlah partikel yang dihasilkan pada batang rokok ini berdasarkan waktu yang di tempu selama pembakaran dapat dilihat pada Gambar 5.

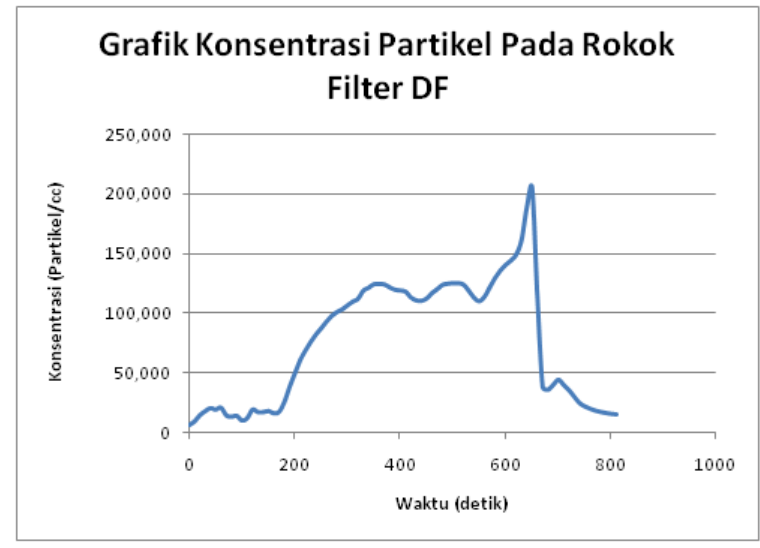

Gambar 5. Grafik Filter DF

Diketahui waktu total pengukuran rokok filter DF adalah $\mathrm{t}=810 \mathrm{~s}$

$$
\begin{aligned}
\mathrm{P}_{\mathrm{t}}=\int_{t(0)}^{t(n)} C(t) \cdot d t=C t \\
=62.479 .720 \frac{\mathrm{pt}}{c c} \mathrm{~s} \\
\mathrm{~V}_{\text {total }} \quad=\mathrm{Q}_{\text {total } \mathrm{X} \mathrm{t}} \\
=7,18 \times 10^{-3} \frac{\mathrm{cm}^{3}}{\mathrm{~s}} \times 810 \mathrm{~s} \\
=5,82 \mathrm{~cm}^{3} \\
\mathrm{E}_{\mathrm{p}} \quad=\mathrm{P}_{\mathrm{t}} \frac{V_{\text {total }}}{T_{\text {total }}} \\
=62.479 .720 \frac{\mathrm{pt}}{\mathrm{cm}^{3}} \mathrm{~s} \frac{5,82 \mathrm{~cm}^{3}}{810 \mathrm{~s}} \\
=448.928,36 \mathrm{pt} \approx 448.928 \mathrm{pt}
\end{aligned}
$$

Faktor emisi partikel yang dikeluarkan pada rokok filter DF adalah $448.928 \mathrm{pt}$

Tabel 1 adalah emisi partikel yang dikeluarkan pada beberapa filter rokok.

Tabel 1. Emisi Partikel Pada Masing-Masing Filter

\begin{tabular}{|c|c|c|c|}
\hline \multicolumn{4}{|c|}{ Partikel Asap Rokok (pt) } \\
\hline Filter X & Filter B & $\begin{array}{c}\text { Filter } \\
\text { DE }\end{array}$ & $\begin{array}{c}\text { Filter } \\
\text { DF }\end{array}$ \\
\hline 179.676 & 667.224 & 646.363 & 448.928 \\
\hline
\end{tabular}

\section{Karakteristik Pengukuran Konsentrasi Partikel Asap Rokok}

Pada Gambar 6 dapat lihat konsentrasi partikel pada semua filter rokok, yang dapat di tampilkan. 


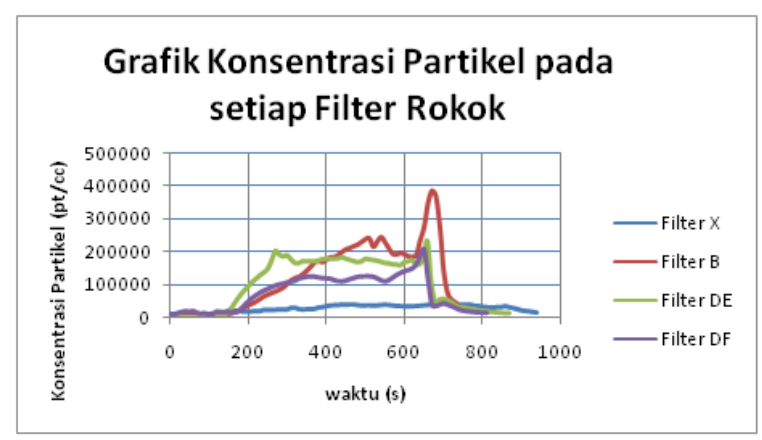

Gambar 6. Konsentrasi Partikel setiap Filter Rokok

\section{a. Filter $\mathbf{X}$}

Pengukuran partikel asap rokok saat pengukuran dimulai dapat dinyatakan jumlah konsentrasi partikel minimum $7.343 \mathrm{pt} / \mathrm{cm}^{3}$ dan maksimum $43.320 \mathrm{pt} / \mathrm{cm}^{3}$. Konsentrasi partikel rata-rata $26.338 \mathrm{pt} / \mathrm{cm}^{3}$. Dari data tersebut dapat diketahui tingkat bahaya partikel asap rokok sebanding dengan banyaknya asap rokok yang masuk ke detektor. Semakin banyak asap rokok yang masuk di dalam detektor maka tingkat konsentrasi partikel asap rokok akan semakin tinggi. Hal ini terbukti dari hasil pengukuran yang telah dilakukan dengan menggunakan alat P-Trak pada rokok Filter - X. Setelah rokok habis terbakar maka dengan cepat akan kembali pada kondisi minimum. Hal ini di sebabkan karena saat rokok habis terbakar akan dimatikan sehingga mengakibatkan asap rokok yang mengalir mulai berkurang dan pada waktu tertentu akan berhenti.

\section{b. Filter B}

Pengukuran dengan menggunakan Filter $\mathrm{B}$, partikel asap rokok saat pengukuran dimulai dapat dinyatakan jumlah konsentrasi partikel minimum $3.534 \mathrm{pt} / \mathrm{cm}^{3}$ dan maksimum $384.100 \mathrm{pt} / \mathrm{cm}^{3}$. Konsentrasi partikel rata-rata $123.979 \mathrm{pt} / \mathrm{cm}^{3}$. Dari data tersebut dapat diketahui tingkat bahaya partikel asap rokok sebanding dengan banyaknya asap rokok yang masuk ke detektor. Semakin banyak asap rokok yang masuk di dalam detektor maka tingkat konsentrasi partikel asap rokok akan semakin tinggi. Hal ini terbukti dari hasil pengukuran yang telah dilakukan dengan menggunakan alat P-Trak pada rokok Filter - B. Setelah rokok habis terbakar maka dengan cepat akan kembali pada kondisi minimum. Hal ini di sebabkan karena saat rokok habis terbakar akan dimatikan sehingga mengakibatkan asap rokok yang mengalir mulai berkurang dan pada waktu tertentu akan berhenti.

\section{c. Filter DE}

Pengukuran dengan menggunakan Filter DE, partikel asap rokok saat pengukuran dimulai, dapat dinyatakan jumlah konsentrasi partikel minimum $1.102 \mathrm{pt} / \mathrm{cm}^{3}$ dan maksimum $234.000 \mathrm{pt} / \mathrm{cm}^{3}$. Konsentrasi partikel rata-rata $102.234 \mathrm{pt} / \mathrm{cm}^{3}$. Dari data tersebut dapat diketahui tingkat bahaya partikel asap rokok sebanding dengan banyaknya asap rokok yang masuk ke detektor. Semakin banyak asap rokok yang masuk di dalam detektor maka tingkat konsentrasi partikel asap rokok akan semakin tinggi. Hal ini terbukti dari hasil pengukuran yang telah dilakukan dengan menggunakan alat P-Trak pada rokok Filter - DE. Setelah rokok habis terbakar maka dengan cepat akan kembali pada kondisi minimum. Hal ini di sebabkan karena saat rokok habis terbakar akan dimatikan sehingga mengakibatkan asap rokok yang mengalir mulai berkurang dan pada waktu tertentu akan berhenti.

\section{d. Filter DF}

Pengukuran dengan menggunakan Filter DE, partikel asap rokok saat pengukuran dimulai, dapat dinyatakan jumlah konsentrasi partikel minimum $6616 \mathrm{pt} / \mathrm{cm}^{3}$ dan maksimum $204.400 \mathrm{pt} / \mathrm{cm}^{3}$. Konsentrasi partikel rata-rata $76195 \mathrm{pt} / \mathrm{cm}^{3}$. Dari data tersebut dapat diketahui tingkat bahaya partikel asap rokok sebanding dengan banyaknya asap rokok yang masuk ke detektor. Semakin banyak asap rokok yang masuk di dalam detektor maka tingkat konsentrasi partikel asap rokok akan semakin tinggi. Hal ini terbukti dari hasil pengukuran yang telah dilakukan dengan menggunakan alat P-Trak pada rokok Filter - DF. Setelah rokok habis terbakar maka dengan cepat akan kembali pada kondisi minimum. Hal ini di sebabkan karena saat rokok habis terbakar akan dimatikan sehingga mengakibatkan asap rokok yang mengalir mulai berkurang dan pada waktu tertentu akan berhenti.

\section{KESIMPULAN}

Berdasarkan hasil analisa data yang didapatkan selama penelitian dapat diambil kesimpulan sebagai berikut: 
1. Faktor emisi partikel asap rokok yang dikeluarkan oleh batang rokok filter B lebih besar dibanding dengan filter lain oleh karena pada masing-masing filter memiliki karakteristik yang berbeda sehingga asap yang dikeluarkan akan sangat berbeda.

2. Dari data tersebut dapat diketahui tingkat bahaya partikel asap rokok sebanding dengan banyaknya asap rokok yang masuk ke detector. Semakin banyak asap rokok yang masuk di dalam detektor maka tingkat konsentrasi partikel asap rokok akan semakin tinggi.

3. Konsentrasi partikel asap rokok yang terukur dengan menggunakan beberapa filter didapatkan bahwa dengan menggunakan Filter B akan mendapatkan konsentrasi partikel paling tinggi yaitu $384.100 \mathrm{pt} / \mathrm{cc}$ sedangkan Filter DE konsentrasi partikel $234.000 \mathrm{pt} / \mathrm{cc}$ untuk Filter DF konsentrasi partikel 204.400 $\mathrm{pt} / \mathrm{cc}$ dan Filter $\mathrm{X}$ konsentrasi partikel $43.320 \mathrm{pt} / \mathrm{cc}$.

4. Metode yang dilakukan ini dapat pula dikembang dengan perilaku yang sama untuk sampel asap hasil pembakaran lainnya.

\section{DAFTAR PUSTAKA}

Daher, N., R. Saleh, E. Jaroudi, H. Sheheitli, T. r. s. Badr, E. Sepetdjian, M. A. Rashidi, N. Saliba dan A. Shihadeh. 2009. Comparison of carcinogen, carbon monoxide, and ultrafine particle emissions from narghilewaterpipe and cigarette smoking: Sidestream smoke measurements and assessment of secondhand smoke emission factors. Atmospheric Environment: 1-2.

Imansyah Ibnu Hakim, Bambang Suryawan, I Made K. , Nandy Putra. Karakterisasi thermal precipitator sebagai smoke Collector dengan menggunakan gas sensor. Departement of Mechanical Engineering Faculty of Engineering University of Indonesia

Pappas, R. S., G. M. Polzin, L. Zhang, C. H. Watson, D. C. Paschal dan D. L. Ashley. 2006. Cadmium, lead, and thallium in mainstream tobacco smoke particulate.Food and Chemical Toxicology. 44: 714-715.

Susanna, D et al., Penentuan Kadar Nikotin. Dalam Asap Rokok, Jurnal Ilmiah Makara, Vol.7 No.2 Desember 2003 Seri Kesehatan

Young, T., J. McAughey, C. Mocker, C. McGrath dan R. Zimmermann. 2010. Influence of filter ventilation on the chemical composition of cigarette mainstream smoke. Analytica Chimica $\operatorname{Acta}(36-44)$.

Tian, B., P. Chen, J. Chen dan L. Bai. 2009. Blocking and filtering effect of Bombyx morisilkworm silk fiber filter tips against mainstream smoke of cigarettes. Materials and Design. 30: 2289-2294. 